\title{
Block Efficacy Above The Clavicle : Volume Of Local Anaesthetic Agents
}

\author{
T. Sivashanmugam ${ }^{1}$, Archana Areti ${ }^{1}$ \\ ${ }^{1}$ Department of Anaesthesiology, Mahatma Gandhi Medical college and Research Institute, \\ Sri Balaji Vidyapeeth Deemed-to-be University, Puducherry, India.
}

\section{Introduction}

The regional anaesthesiologist's primary goal is to deposit adequate local anaesthetic (LA) in the vicinity of nerves for the desired effect without complications. Our inability to visualise nerves, during landmark and peripheral nerve stimulation techniques, was the biggest obstacle against accurate deposition. Ultrasound (US) guidance enables accurate deposition of local anaesthetics due to objective and consistent visualisation of target nerves [1]. However, the minimum effective local anaesthetic volume (MELAV) varies among clinicians. Stephan Kapral in 1994 described the first ultrasound-guided supraclavicular brachial plexus block [2]. However, the image quality and the injection technique similar to our present-day practice appeared in 2003, where Vincent Chan et al injected $40 \mathrm{ml}$ of local anaesthetic (LA) volume to achieve a 95\% success rate [3]. This article reviews the studies that explored the MELAV for US-guided brachial plexus blocks (BPB) above the clavicle and explores the possible reasons for variations reported by authors and to direct future research for identification of safe and effective local anaesthetic volume for the BPB above the clavicle.

\section{Minimum Alveolar Concentration (MAC) versus MELAV}

In 1965 Eger et al introduced the concept of MAC for quantification of inhalational agent required for effective general anaesthesia [4]. To identify the MAC, a known concentration of agent (percentage of gas mixture) was administered through the lungs and a single objective response i.e. movement, was observed to a standard stimulus i.e skin incision. The minimum concentration that inhibits movement in $50 \%$ of individuals was labelled MAC of that particular agent. In regional anaesthesia, MELAV is used to express the minimum amount of local anaesthetic required for an effective peripheral nerve block. However, the determination of MELAV is more complex than MAC for the following reasons:

1. The partial pressure of the agent determines the clinical outcome, and since it is directly proportional to concentration, manipulating the concentration of the administered agent linearly affects the outcome. However to achieve successful nerve conduction blockade, both LA volume and concentration influence outcomes. Literature states that conduction blockade across a nerve fibre requires involvement of more than $70 \%$ of sodium channels over three consecutive nodes of Ranvier and considering that internodal distances range from 0.2 to $2 \mathrm{~mm}[5,6]$ a minimum $6 \mathrm{~mm}$ length of nerve would need to be exposed for blockade. The volume administered act a vehicle to carry the LA molecule across $6 \mathrm{~mm}$ length of nerve, at the same time concentration (number of molecules present per unit volume) should be adequate enough to occupy $70 \%$ of the receptors so that impulse conduction can be blocked.

2. Inhalational agents are administered to the lungs is via breathing circuits. Factors affecting agent delivery, such as fresh gas flow, dial setting, and minute ventilation are very much predictable and easy to standardize. Whereas during peripheral and plexus nerve blockade, the block outcomes vary significantly based on the injection technique adapted i.e single point vs. multipoint injections and the site of drug deposition (extrafacial vs subfacial).

Address of Correspondence: Dr. T. Sivashanmugam, Professor, Department of Anaesthesiology, Mahatma Gandhi Medical college and Research Institute, Sri Balaji Vidyapeeth Deemed-to-be University, Puducherry, India. E-mail: drsiva95@gmail.com

DOI: 10.13107/ijra.2021.v02i01.024 | (C) 2021 International Journal of Regional Anaesthesia | Available on www.ijrajournal.com | This is an Open Access article distributed under the terms of the Creative Commons Attribution Non-Commercial License (http://creativecommons.org/licenses/by-nc/3.0) which permits unrestricted non-commercial use, distribution, and reproduction in any medium, provided the original work is properly cited.

How to cite this article: Sivashanmugam T, Areti A | Block Efficacy Above The Clavicle : Volume Of Local Anaesthetic Agents | International Journal of Regional Anaesthesia | January-June 2021; 2(1): 35-39. 
3. MAC assessment relied on movement in response to skin incision as the only outcome, whereas for PNB both the stimulus (soft tissue or bony procedures) and the outcome (analgesia or anaesthesia) varied across different studies, investigating the MELAV.

\section{Methodologies evaluating the MELAV for US-guided BPB above the clavicle}

Till date, to the best of our knowledge, nine articles analysed the MELAV for US-guided BPB above the clavicle (Table 1). The MELAV 95 reported ranges from as low as $5 \mathrm{ml}$ to 42 $\mathrm{ml}$. Three methodologies have been used, in these studies, for identifying MELAV. Dixon-Mood (DM) up-and-Down method remains the most prevalent, however few studies have used the Biased Coin Design (BCD) variant Bayesian analysis and Continual Reassessment Method (CRM). The advantage of DM up-and-down method is the requirement of smaller sample size; however it measures only to the $50^{\text {th }}$ quantile (ED 50- Effective dose) and estimates the ED 90/95/99 resulting in a measurement that is weak in accuracy [7]. On the other hand, the BCD and CRM methods directly measure higher quantiles (ED 90/95/99) but require larger sample sizes. Even though the ED 50 is sufficient to measure potency and compare pharmacological agents, during peripheral nerve blockade, the dose that provides $95 \%$ success rate (ED 90/95) is clinically more relevant than ED 50. So this review focussed on studies reporting MELAV 90/95.

A single intervention with different outcomes, reflects the fact that multiple factors are responsible for the cause effect relationship, in order to define a MELAV. We discuss the influencing factors according to the degree of impact they have in every day clinical practice at the authors discretion.

\section{Pharmacological}

The number of LA molecules needed to block $70 \%$ sodium channels over three consecutive nodes of Ranvier is influenced by the LA's potency, which in turn impacts the MELAV. For example, MELAV of a local anaesthetic with low potency like lidocaine $1.5 \%$ was $32 \mathrm{ml}$ [8], whereas LA with higher potency like ropivacaine $0.5 \%$ required only 15 $\mathrm{ml}$ [9]. Even different concentrations of the same local anaesthetic, resulted in different volumes to produce the same conduction blockade, evidenced by a study investigating the US-guided supraclavicular BPB where $0.5 \%, 0.375 \%$ and $0.25 \%$ concentrations of bupivacaine, required 17,26 , and $38 \mathrm{ml}$ respectively, for a successful block [10]. This observation reflects the physical principle, that as concentration reduces, more volume of LA would be needed to soak the length of the nerve for effective conduction blockade [11]. Finally the role of adjuvants, that are claimed to hasten onset or prolong the duration, may influence the pharmacodynamics of LA thereby affecting the MELAV.

\section{Technique for drug deposition}

The technique for LA deposition varied, across the studies, from a single to multipoint injections or deposition around or within the brachial plexus sheath. Studies with single point injections observed the MELAV was $42 \mathrm{ml}$ [12] which fell to $32 \mathrm{ml}$ when a double point injection was performed (50\% at corner pocket and $50 \%$ at the middle of the nerve cluster) [8] and fell further to $17 \mathrm{ml}$ when multiple points injections were performed across all the nerve clusters [13]. When LA was deposited within the brachial plexus sheath (subfacial injection), the presenting authors found that the time to readiness for surgery was hastened by 13 minutes, when compared with LA deposition around the sheath(extrafacial injection) ( $7 \pm 3$ versus $20 \pm 10$ minutes; $\mathrm{P}=0.000)$ [14]. The authors also found by following a selective truncal approach, of all three trunks with an equal mixture of $2 \%$ lidocaine with adrenaline and $0.5 \%$ bupivacaine, the MELAV was $10 \mathrm{ml}$ [15]. When there is so much variation in the dynamics of BPB even under direct visualisation through US guidance, the MELAV determined from these studies may not be applicable for surface landmark or PNS guided BPB techniques, and goes beyond the scope of this review.

\section{Defining the block outcome}

The spectrum of conduction blockade ranges from normal sensory-motor function to complete absence of both i.e complete conduction blockade(CCB), where analgesia and surgical anaesthesia are placed in-between. The differential blockade property of LA can result complete loss of sensory function at the dermatome, which may not necessarily correlate with a complete blockade at the myotome or osteotome, which would not be considered as CCB. So one may obtain adequate surgical anaesthesia at the forearm, however not considered as CCB, as movement of the fingers maybe intact. Hence analgesia [16], time to readiness for surgery [14], surgical anaesthesia [8] and complete conduction blockade [15] should be taken as different endpoints requiring different MELAV.

\section{Anatomical}

The number of axons exiting the spinal cord reorganise into multiple fascicles as they traverse from central neuraxis to form peripheral nerves. During their course the average number of fascicles in the BP increased from 29 at the trunks 


\begin{tabular}{|c|c|c|c|c|c|c|c|c|c|c|}
\hline & نे & 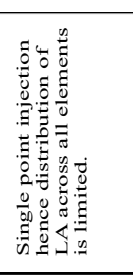 & 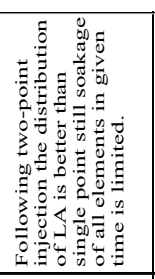 & 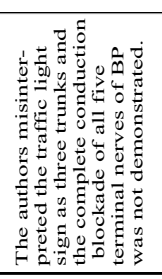 & 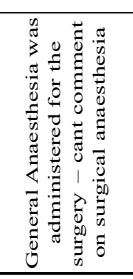 & 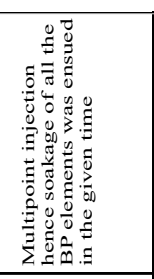 & 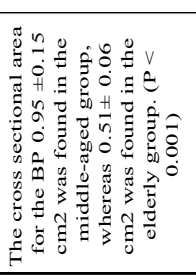 & 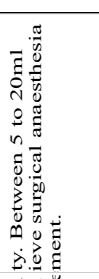 & 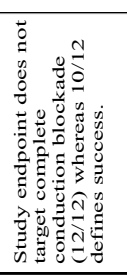 & 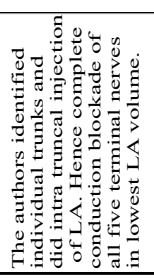 \\
\hline & 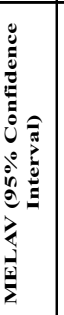 & 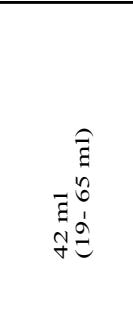 & 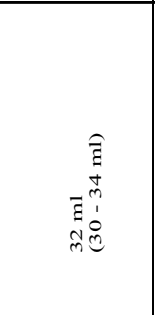 & 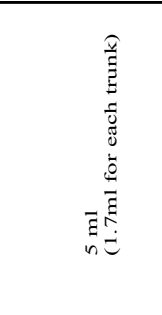 & 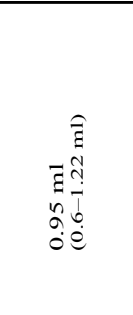 & 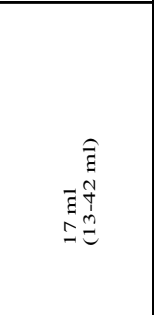 & 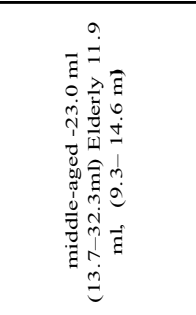 & 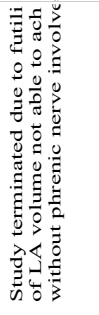 & $\begin{array}{c}\bar{\Xi} \\
\underline{n}\end{array}$ & $\begin{array}{l}\bar{g} \\
f \\
\stackrel{f}{0}\end{array}$ \\
\hline & 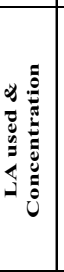 & 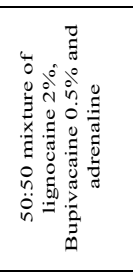 & 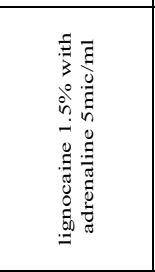 & 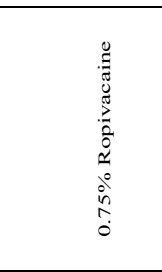 & 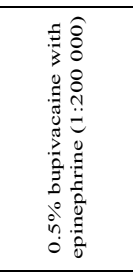 & 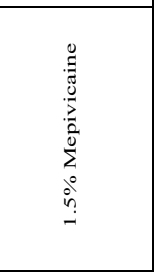 & 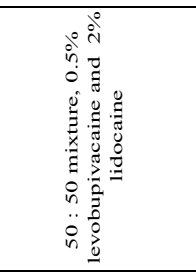 & 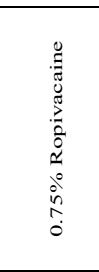 & 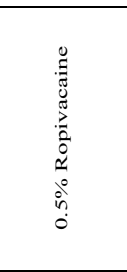 & 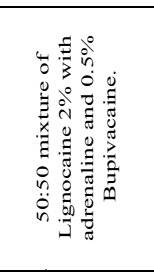 \\
\hline & 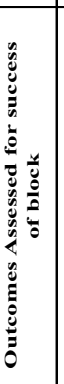 & 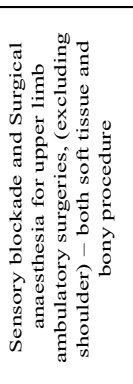 & 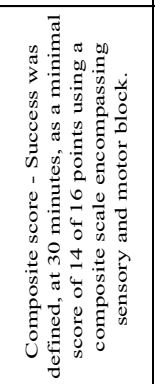 & 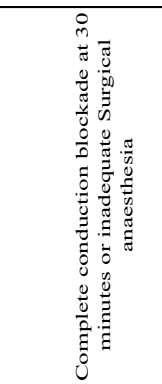 & 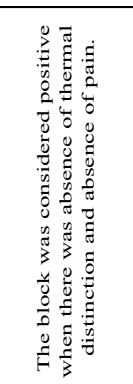 & 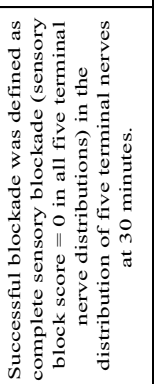 & 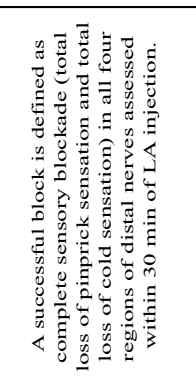 & 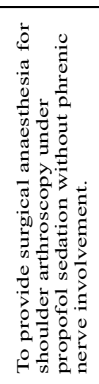 & 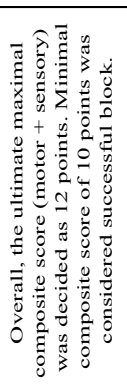 & 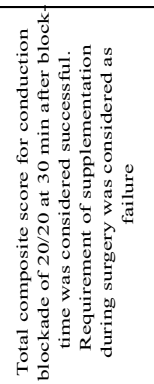 \\
\hline & 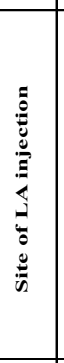 & 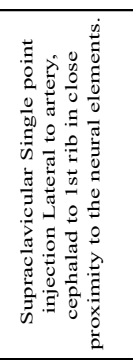 & 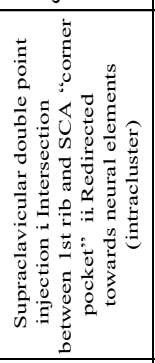 & 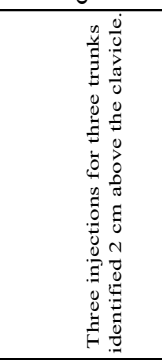 & 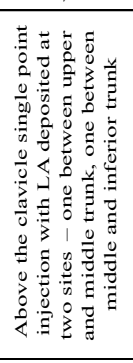 & 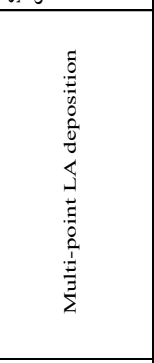 & 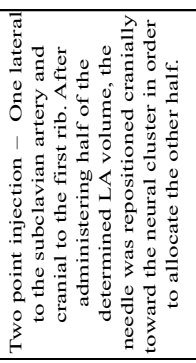 & 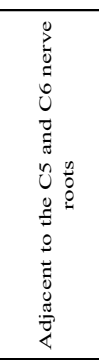 & 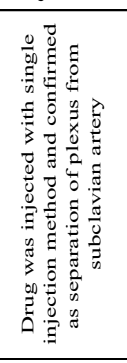 & 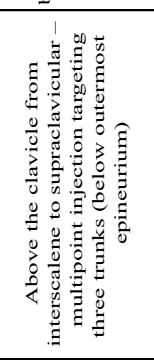 \\
\hline & 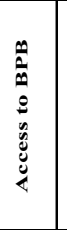 & 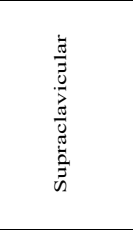 & 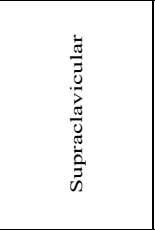 & $\begin{array}{l}\frac{0}{0} \\
\frac{0}{\tilde{g}} \\
\frac{0}{0} \\
\frac{0}{0} \\
\Xi\end{array}$ & $\frac{0}{5}$ & 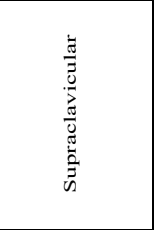 & 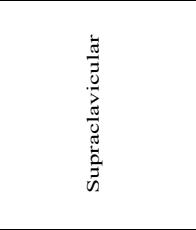 & 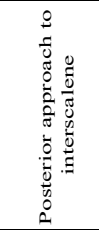 & 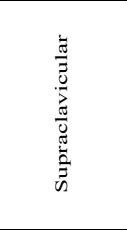 & 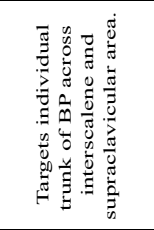 \\
\hline & 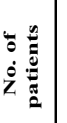 & $\overline{\text { ते }}$ & $\stackrel{+}{n}$ & iे & $\eta$ & in & J & in & ते & $\overline{\mathrm{d}}$ \\
\hline 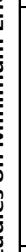 & 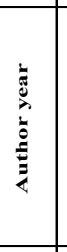 & 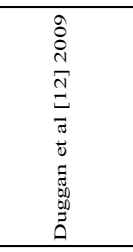 & 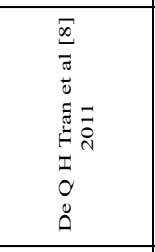 & 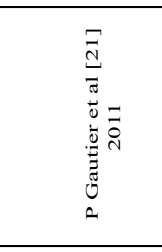 & 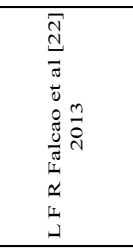 & 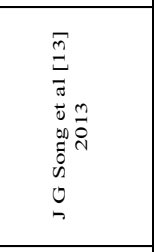 & 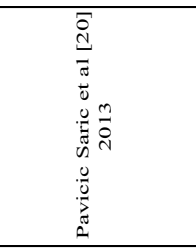 & 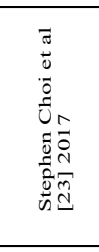 & 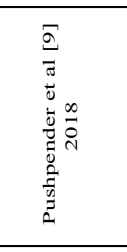 & 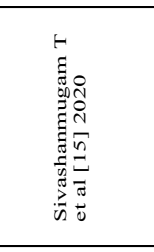 \\
\hline تِ & 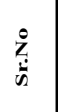 & - & i & $\dot{m}$ & $\dot{r}$ & $\dot{r}$ & 0 & $r$ & $\dot{\infty}$ & $\sigma^{\circ}$ \\
\hline
\end{tabular}


to 46 at the level of cords. Correspondingly volume of connective tissue has been reported to increase from $28 \%$, $58 \%$ and $90 \%$ at the roots, trunks and terminal peripheral nerves respectively [17]. The ratio of neural to non-neural connective tissue has been reported to impact the block dynamics [18], as it may reflect the amount of resistance to the spread and distribution of LA [19]. Hence, the MELAV used for the truncal block at the supraclavicular fossa may not be applicable to blockade of the cords at the costoclavicular space or peripheral nerve block at the level of axillary crease.

\section{Physiological}

Individual patients' characteristics like age, sodium channel density, subtype, and sensitivity to local anaesthetics can affect the MELAV for the desired outcome. J. Pavicic Saric et al demonstrated that the MELAV 50\% of the middle-aged (42 \pm 6$)$ patients was $23 \mathrm{ml}(95 \% \mathrm{CI} 13.7-32.3 \mathrm{ml})$, whereas the MELAV 50 of elderly $(75 \pm 7)$ patients were $11.9 \mathrm{ml}$ (95\% CI 9.3 - $14.6 \mathrm{ml}, \mathrm{P}=0.027$ ) during US-guided supraclavicular BPB [20]. They associated the less MELAV to the deterioration changes in the neuronal system reflected by the smaller surface area of the BP at the first rib in elderly patients $\left(0.51 \pm 0.06 \mathrm{~cm}^{2}\right.$ vs $\left.0.95 \pm 0.15 \mathrm{~cm}^{2}\right)$. Because of this myriad of genetic and interindividual variation, at any given MELAV, some individuals may not attain the same block outcome.

\section{Direction for future research}

Since MELAV is affected by the type of drug, volume, concentration, deposition site, injection technique adapted, outcome assessed, adjuvants added and individual patient's susceptibility, studying them randomly will provide innumerable permutations of combinations, which is not only impractical but also will not provide any conclusive evidence for clinical application. Based on the ten years of experience in brachial plexus block research, the authors suggest a systematic approach to explore the MELAV for $\mathrm{BPB}$ above the clavicle. Among the various factors discussed, the two in clinicians' gambit are technical approach and blockade outcome assessment.

Hence clinicians embarking on MELAV studies may adopt the following steps:

1. Adopt an injection technique that distributes local anaesthetics across all the neural elements and provides consistent results even in difficult sonoanatomy. The injection technique and the clinician experience should be such that incomplete conduction blockade is only due to drug characteristics not due to faulty technique. (The competence of the block performer is a major bias factor to be standardized)
2. Choose commonly used LA or LA combinations (Be aware that intrinsic properties of LA can impact the block outcomes - for e.g. at low volumes, lignocaine may not last the surgical duration, whereas bupivacaine has a prolonged onset time to achieve surgical anaesthesia (>30minutes) which is not viable in clinical practice - Unpublished data)

3. Choose clear objective endpoints in the spectrum of conduction blockade (Composite score/complete conduction blockade) to reduce inter-observer bias. (Since there is no universally accepted ideal duration of surgical anaesthesia and analgesia for a given block, the meaning of the word "effective" in the MELAV commonly represent the onset and quality of surgical anaesthesia. Hence the MELAV that satisfies the onset characteristics may not last long and may not guarantee complication-free regional anaesthesia)

4. Reduce the study cohort's variations, standardise the surgical stimulus (bony procedures) so that the MELAV identified in this cohort can be extrapolated to the population with minimal modifications.

\section{Avoid use of adjuvants}

(Dexamethasone/Clonidine/Opioids) until pharmacodynamics of the MELAV are well defined. 6. Once the MELAV of a particular agent or combination of agents is identified, it must be prospectively observed in larger populations to describe the block dynamics (Duration of surgical anaesthesia, analgesia and complication profile) and refine the volume to suit the clinical need. Hence the MELAV has to mature into Clinically Effective Local Anaesthetic Volume CELAV.

\section{Conclusion}

Even after introducing ultrasound guidance in regional anaesthesia, the MELAV for BPB above the clavicle is still not established. However, the minimum safe and effective volume continues to reduce as our understanding of $\mathrm{BP}$ sonoanatomy improves, and consistency of targeted component blockade evolves. The authors recommend the readers to adopt a systematic approach to study and comprehend the MELAV findings. 


\section{References}

1. Karmakar MK, Pakpirom J, Songthamwat B, Areeruk P. High definition ultrasound imaging of the individual elements of the brachial plexus above the clavicle. Regional Anesthesia \& Pain Medicine. 2020 May;45(5):344-50.

2. Eger EI, Saidman LJ, Brandstater B. Minimum Alveolar Anesthetic Concentration. Anesthesiology. 1965 Nov 1;26(6):756-63.

3. Strichartz GR, Pastijn E, Sugimoto K. Neural physiology and local anesthetic action. In: Cousins MJ, Carr DB, Horlocker TT, Bridenbaugh PO, editors. Cousins and Bridenbaugh's Neural Blockade in Clinical Anaesthesia and Pain Medicine. 4thed. Lippincott Williams \& Wilkins; 2012.41-43p.

4. Berthold CH, Martin R, Waxman SG, Kocsis JD, Stys PK. Morphology of normal peripheral axons. In: The Axon [Internet]. Oxford University Press; 1995 [cited $2021 \mathrm{Jan} \mathrm{15}$ ]. 22-4 p. Available from: http://www.oxfordscholarship.com/view/10.1093/acprof:oso/978019508 2937.001.0001/acprof-9780195082937

5. Kapral S, Krafft P, Eibenberger K, Fitzgerald R, Gosch M, Weinstabl C. Ultrasound-Guided Supraclavicular Approach for Regional Anesthesia of the Brachial Plexus: Anesthesia \& Analgesia. 1994 Mar;78(3):507???513.

6. Chan VWS, Perlas A, Rawson R, Odukoya O. Ultrasound-Guided Supraclavicular Brachial Plexus Block: Anesthesia \& Analgesia. 2003 Nov;1514-7.

7. Saranteas T, Finlayson RJ, Tran DQH. Dose-Finding Methodology for Peripheral Nerve Blocks: Regional Anesthesia and Pain Medicine. 2014;39(6):550-5.

8. Tran DQH, Dugani S, Correa JA, Dyachenko A, Alsenosy N, Finlayson RJ. Minimum Effective Volume of Lidocaine for Ultrasound-Guided Supraclavicular Block: Regional Anesthesia and Pain Medicine. 2011 Sep;36(5):466-9.

9. Prateek P. Estimation of Minimum Effective Volume of Ropivacaine $0.5 \%$ in Ultrasound Guided Supraclavicular Brachial Plexus Nerve Block: A Prospective Clinical Trial. Journal of Anesthesia \& Intensive Care Medicine [Internet]. $2018 \mathrm{Feb} 27$ [cited $2021 \mathrm{Jan}$ 11];5(5). Available from: https://juniperpublishers.com/jaicm/JAICM.MS.ID.555671.php

10. Gupta PK, Hopkins PM. Effect of concentration of local anaesthetic solution on the ED 50 of bupivacaine for supraclavicular brachial plexus block ++ Preliminary data from this study were presented to a meeting of Anaesthetic research society and European Society of Regional Anaesthesia. British Journal of Anaesthesia.2013 Aug;111(2):293-6.

11. Raymond SA, Scott c.Steffensen, Laverne D. Gugino, Gary R. Strichartz. The Role of Length of Nerve Exposed to Local Anesthetics in Impulse Blocking Action. Anesthesia \& Analgesia. 1989; (68):563-70.

12. Duggan E, El Beheiry H, Perlas A, Lupu M, Nuica A, Chan VWS, et al. Minimum Effective Volume of Local Anesthetic for Ultrasound-Guided Supraclavicular Brachial Plexus Block: Regional Anesthesia and Pain Medicine.2009 May;34(3):215-8.

13. Song JG, Jeon DG, Kang BJ, Park KK. Minimum effective volume of mepivacaine for ultrasound-guided supraclavicular block. Korean Journal of Anesthesiology. 2013;65(1):37.

14. Sivashanmugam T, Ray S, Ravishankar M, Jaya V, Selvam E, Karmakar MK. Randomized Comparison of Extrafascial Versus Subfascial Injection of Local Anesthetic During Ultrasound-Guided Supraclavicular Brachial Plexus Block: Regional Anesthesia and Pain Medicine. 2015;40(4):337-43.
15. Sivashanmugam T, R S, J G, R C, MR. Truncal injection brachial plexus block: A Description of a novel injection technique and dose finding study. Indian Journal of Anaesthesia. 2020;64(5):415-21.

16. Fredrickson MJ, Smith KR, Wong AC. Importance of Volume and Concentration for Ropivacaine Interscalene Block in Preventing Recovery Room Pain and Minimizing Motor Block after Shoulder Surgery. Anesthesiology.2010Jun 1;112(6):1374-81.

17. Bonnel F. Microscopic anatomy of the adult human brachial plexus: An anatomical and histological basis for microsurgery. Microsurgery. 1984;5(3):107-17.

18. Moayeri N, Bigeleisen PE, Groen GJ. Quantitative Architecture of the Brachial Plexus and Surrounding Compartments, and Their Possible Significance for Plexus Blocks. Anesthesiology. 2008 Feb 1;108(2):299-304.

19. Cornish PB, Leaper CJ, Hahn JL. The Axillary Tunnel: An Anatomic Reappraisal of the Limits and Dynamics of Spread During Brachial Plexus Blockade: Anesthesia \& Analgesia. 2007 May;104(5):1288-91.

20. Pavičić Šarić J, Vidjak V, Tomulić K, Zenko J. Effects of age on minimum effective volume of local anesthetic for ultrasound-guided supraclavicular brachial plexus block: Brachial plexus block in the elderly. Acta Anaesthesiologica Scandinavica.2013 Jul;57(6):761-6.

21. Gautier P, Vandepitte C, Ramquet C, DeCoopman M, Xu D, Hadzic A. The Minimum Effective Anesthetic Volume of $0.75 \%$ Ropivacaine in Ultrasound-Guided Interscalene Brachial Plexus Block: Anesthesia \& Analgesia.2011 Oct;113(4):951-5.

22. Falcão LFR, Perez MV, de Castro I, Yamashita AM, Tardelli MA, Amaral JLG. Minimum effective volume of $0.5 \%$ bupivacaine with epinephrine in ultrasound-guided interscalene brachial plexus block. British Journal of Anaesthesia. 2013 Mar;110(3):450-5.

23. Choi S, Wang JJ, Awad IT, McHardy P, Safa B, McCartney CJ. The minimal effective volume (MEAV95) for interscalene brachial plexus block for surgical anesthesia under sedation: A prospective observational dose finding study. Canadian Journal of Pain. 2017 Jan 1;1(1):8-13. 